\title{
Coughing frequency in patients with persistent cough: assessment using a 24 hour ambulatory recorder
}

\author{
J.Y. Hsu*†, R.A. Stone*, R.B. Logan-Sinclair**, \\ M. Worsdell*, C.M. Busst**, K.F. Chung*
}

Coughing frequency in patients with persistent cough: assessment using a 24 hour ambulatory recorder. J.Y. Hsu, R.A. Stone, R.B. Logan-Sinclair, M. Worsdell, C.M. Busst, K.F. Chung. CERS Journals Ltd 1994.

ABSTRACT: Cough is an important symptom of many respiratory disorders. We determined the frequency and diurnal variation of cough in normal subjects and in patients with asthma or with persistent cough of unknown cause.

We used a portable, solid-state, multiple-channel recorder to record cough sounds over a $24 \mathrm{~h}$ period. The audio-signal was recorded from a unidirectional microphone strapped over the chest wall, and electromyographic (EMG) signals from the lower respiratory muscles were simultaneously registered with surface electrodes. The recorded digital data were examined on an IBM-compatible computer, and the typical signals induced by cough (as assessed by voluntary or experimentally-induced cough) were counted.

In 12 normal subjects, only 0-16 coughs were recorded over $24 \mathrm{~h}$. In 21 stable asthmatics with a history of chronic cough ("asthma") the median number was 282 (ranges: 45-1,577), and in 14 patients with the predominant symptom of daily dry coughs ("chronic coughers") the median number was $794(64-3,639)$. In both groups of patients, there was a diurnal variation of coughs, such that the least numbers occurred between 2 and 5 a.m. ( $<3 \%$ of total). In the asthma group, there was no significant correlation between forced expiratory volume in one second $\left(\mathrm{FEV}_{1}\right)$ (\% predicted) or diurnal variation of peak expiratory flow and cough frequency. In the chronic coughers, there was a significant correlation between daytime cough numbers and daytime cough symptom scores but not for the night-time values.

Our data show that cough frequency is not determined by the severity of asthma in relatively stable asthmatics on inhaled steroids, and is reduced during sleep in both asthmatics and chronic cough patients. This portable cough recorder may be useful in the assessment of drug therapy for chronic cough.

Eur Respir J., 1994, 7, 1246-1253.

Cough is an important symptom of many respiratory disorders. It may be the only presenting symptom of asthma [1], as it may be the earliest symptom, particularly during the night, to indicate worsening of asthma [2]. In addition, cough may be a persistent symptom without any identifiable causes [3]. Assessment of cough severity has usually depended on asking the patient for his perception of this symptom $[4,5]$. Despite previous reports of recording coughing events, there is no current objective system for assessing the frequency and diurnal variation of cough over a $24 \mathrm{~h}$ period in ambulatory patients. Whether the number of coughs is a function of the severity of the disease underlying the cough is not known.

The methods that have previously been described to record cough have mostly been nonambulatory, and usually limited to short periods of time, using visible and auditory changes [6-11]. Some workers have attempted quantitative determination of cough by allotting marks
Dept of *Thoracic Medicine and **Biomedical Engineering, National Heart \& Lung Institute, Royal Brompton Hospital, London, UK, †ivision of Chest Medicine, Taichung Veterans General Hospital, Taichung, Taiwan, R.O.C.

\section{Correspondence: K.F. Chung}

Dept of Thoracic Medicine

National Heart \& Lung Institute

Dovehouse Street

London SW3 6LY UK

Keywords: Asthma

cough

cough recorder

Received: July 121993

Accepted after revision March 271994 over a given period by the nursing staff or by the patient himself $[4,12,13]$. Recording of the pneumogram onto a kymograph has also been used to examine the intensity and duration of cough [14]. Cough was later recorded on a tape-recorder, using microphones either fixed on the wall of the patient's room or placed in close contact with the patient's throat $[15,16]$. In these studies, the effects of antitussive agents were investigated under conditions where the mobility of the patient was restricted to the room. More recently, cough sounds were recorded with a dynamic microphone placed in the acoustic focus of a paraboloid mirror, but this method could only record cough whilst the subject was lying on a bed [17].

We have developed a portable device to record coughing events occurring over a $24 \mathrm{~h}$ period in ambulatory subjects, by making simultaneous recordings of cough sounds and of the electromyograms of the lower respiratory muscles, including diaphragmatic activity. The recordings were processed on an IBM-compatible 
Table 1. - Characteristics of normal subjects and patients

\begin{tabular}{|c|c|c|c|c|c|}
\hline Group & $\begin{array}{l}\text { Sex } \\
\mathrm{M} / \mathrm{F}\end{array}$ & $\begin{array}{l}\text { Age } \\
\text { yrs }\end{array}$ & \multicolumn{2}{|c|}{$\mathrm{FEV}_{1}$} & $\begin{array}{c}\text { Duration of cough } \\
\text { yrs }\end{array}$ \\
\hline $\begin{array}{l}\text { Normal subjects } \\
(\mathrm{n}=12)\end{array}$ & $9 / 3$ & $\begin{array}{c}37 \pm 12 \\
(21-62)\end{array}$ & $3.56 \pm 0.24$ & $\begin{array}{c}100 \\
(88-120)\end{array}$ & \\
\hline $\begin{array}{l}\text { Asthmatic patients* } \\
(\mathrm{n}=21)\end{array}$ & $4 / 17$ & $\begin{array}{l}52 \pm 15 \\
(20-77)\end{array}$ & $2.05 \pm 0.22$ & $\begin{array}{c}77 \\
(26-107)\end{array}$ & $\begin{array}{l}12.7 \pm 12.4 \\
(0.5-50)\end{array}$ \\
\hline $\begin{array}{l}\text { Chronic coughers } \\
(n=14)\end{array}$ & $6 / 8$ & $\begin{array}{c}55 \pm 14 \\
(26-73)\end{array}$ & $2.82 \pm 0.27$ & $\begin{array}{c}91 \\
(43-110)\end{array}$ & $\begin{array}{r}6.3 \pm 6.1 \\
(1.5-20)\end{array}$ \\
\hline
\end{tabular}

Data are presented as mean $\pm \mathrm{SEM}$, and range in parentheses. *: duration of asthma symptoms $19 \pm 15$ yrs (range $0.5-56 \mathrm{yrs}$ ). $\mathrm{FEV}$ : forced expiratory volume in one second.

computer, and the simultaneous digital sound and electromyographic patterns typical of cough were counted.

The aims of the present study were twofold. Firstly, we validated this method of cough counts by using induced and spontaneous coughing events and by examining whether this could be readily distinguished from other extraneous sounds. Secondly, we used this portable system to examine the cough frequency and diurnal variation of cough in patients with stable asthma who complained of a chronic cough, in patients whose predominant symptom was that of a nonproductive cough with no cause determined at initial presentation, and in normal asymptomatic volunteers.

\section{Methods}

\section{Subjects and patients}

We studied 12 normal subjects, 21 stable asthmatic patients with a history of daily nonproductive cough, and 14 patients with a daily persistent nonproductive cough of unknown cause ("chronic cougher") (table 1). All patients had at least a 6 month history of cough. Each subject or patient underwent a $24 \mathrm{~h}$ cough recording.
Asthmatic patients. The diagnosis of asthma was made on the basis of a history of episodic dyspnoea and wheeze, reversible airway obstruction following inhalation of $\beta_{2}$-adrenergic agonist, and bronchial hyperresponsiveness as measured by methacholine challenge test provocative concentration of methacholine producing a $20 \%$ fall in forced expiratory volume in one second $\left(\mathrm{PC}_{20}\right)$ $\left.<8 \mathrm{mg} \cdot \mathrm{ml}^{-1}\right)$. Patients recorded daily symptom scores for asthma symptoms and for cough severity (table 2), and daily morning and evening peak expiratory flow-rate using a mini Wright peak flow meter, over one week. Both daytime and night-time asthma and cough scores were calculated and compared with asthma symptoms and coughs during the day (defined as 5 a.m. to 11 p.m.), and the night (11 p.m. to 5 a.m. the next morning). Mean peak flow variation was calculated from the difference between the morning and evening, and expressed as a percentage of the maximum value over the one week period. All asthmatic patients were on regular inhaled steroid treatment (dose range $800-3200 \mu \mathrm{g}$ of beclomethasone dipropionate or budesonide), and inhaled $\beta_{2}$-agonist as necessary. Three patients needed oral maintenance prednisolone to control their asthma (5-30 $m g \cdot$ day $\left.^{-1}\right)$. None of them had an exacerbation of asthma during the week prior to cough recording. All patients continued with their medication as usual.

Table 2. - Asthma and cough symptom score

\begin{tabular}{|c|c|}
\hline Daytime & Night-time \\
\hline Asthma symptom score & Asthma symptom score \\
\hline $0=$ no symptoms during the day & $0=$ no symptoms during the night \\
\hline $1=$ symptoms for one short period & $1=$ symptoms on waking only \\
\hline $2=$ symptoms more than two short periods & $2=$ wake once or wake early due to symptoms \\
\hline $\begin{array}{l}3=\text { symptoms for most of the day, which did not interfere with } \\
\text { usual daytime activities }\end{array}$ & $3=$ symptoms cause frequent waking in the night \\
\hline $\begin{array}{l}\text { 4=symptoms for most of the day, which did interfere with } \\
\text { usual daytime activities }\end{array}$ & $\begin{array}{l}4=\text { been awake for most of the night by } \\
\text { symptoms }\end{array}$ \\
\hline $5=$ cannot perform usual daytime activities due to severe symptoms & $5=$ cannot sleep at all due to severe symptoms \\
\hline Cough symptom score & Cough symptom score \\
\hline $0=$ no cough during the day & $0=$ no cough during the night \\
\hline $1=$ cough for one short period & $1=$ cough on waking only \\
\hline $2=$ cough for more than two short periods & $2=$ wake once or early due to cough \\
\hline $\begin{array}{l}3=\text { frequent coughing, which did not interfere with usual daytime } \\
\text { activities }\end{array}$ & $3=$ frequent waking due to coughs \\
\hline $4=$ frequent coughing, which did interfere with usual daytime activities & $4=$ frequent coughs most of the night \\
\hline $5=$ distressing coughs most of the day & $5=$ distressing coughs preventing any sleep \\
\hline
\end{tabular}


Chronic cough patients. These patients reported persistent nonproductive cough for at least 6 months, with no symptoms of wheeze or shortness of breath, and with a normal chest radiograph. Each underwent procedures, including pulmonary function tests, methacholine challenge test, cough challenge test with low chloridecontent solution and capsaicin solution, fibreoptic bronchoscopy, computed tomographic scans of paranasal sinuses, and $24 \mathrm{~h}$ oesophageal $\mathrm{pH}$ monitoring. Patients were asked to record daily symptom score for cough severity (table 2).

Following these procedures and in response to specific therapy, two patients had oesophageal reflux, three had postnasal drip due to either paranasal sinusitis or rhinosinusitis, and four (including one with associated postnasal drip) responded well to inhaled steroid therapy but without a history of wheeze or shortness of breath. In the remaining five, no cause was found.

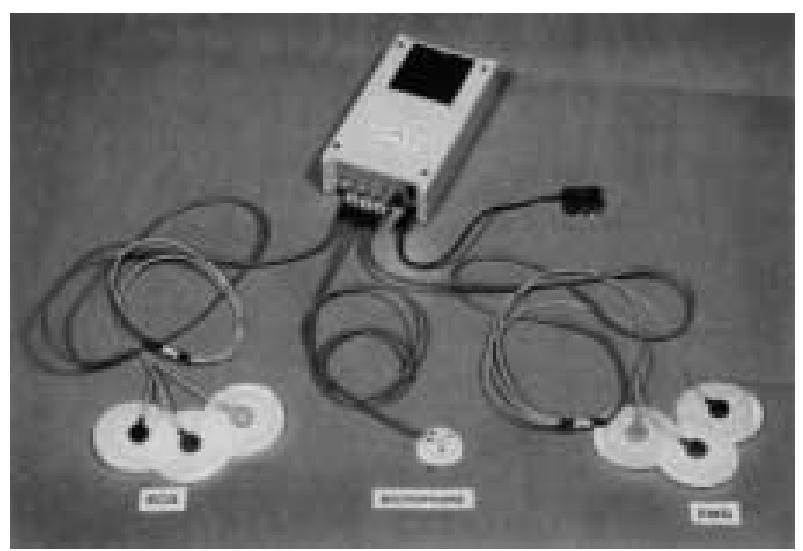

Fig. 1. - The Brompton cough recording system; a 6-volt, batteryoperated, solid-state, 5-channel recorder. ECG: electrocardiogram; EMG: electromyogram

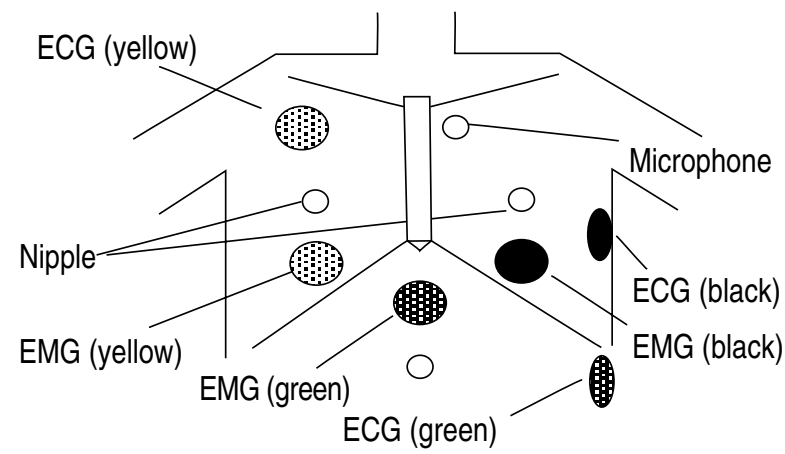

Fig. 2. - Positions of microphone and surface electrodes for electrocardiogram (ECG) and electromyogram (EMG) over the anterior aspect of the thorax. The microphone is placed in the first intercostal space (ICS) at the left sternal border. For ECG electrodes: black 5th ICS in the left axillary line $\left(\mathrm{V}_{6}\right.$ position); yellow - right upper chest; and green - left lateral abdomen. For EMG electrodes: black - 6th ICS, in the left midclavicular line; yellow - 6th ICS, in the right midclavicular line; and green - in epigastrium.

\section{Cough recorder system}

A 6-volt, battery-operated, solid-state, multiple-channel custom digital logger fitted with a two-megabyte random access memory (RAM) (Brompton Cough Recording System, London, UK) was used (fig. 1). Audio signal was recorded from a unidirectional microphone (Knowles type BL1670, Knowles Electronics Co., W. Sussex, UK) attached to the chest wall facing the skin with double-sided adhesive rings. In free air, the microphone has a flat frequency response between 50 and $8 \mathrm{~Hz}$, with some peaking of the response between 1.5 and $5 \mathrm{kHz}$ which further enhances the band pass filtering. Electromyogram (EMG) signals were recorded from surface electrodes. Although the electrocardiogram (ECG) signal was also obtained, it was not analysed. The placement of these electrodes and the microphone over the chest wall is shown in figure 2 .

Custom preprocessing was equivalent to a band pass filter, a full wave rectifier and a signal averaging circuit in series. The band pass filter consisted of separate high pass (HP) and low pass (LP) filters. For the audio signal, HP consisted of a 4-pole HP filter, with a $-3 \mathrm{~dB}$ point at $1.3 \mathrm{kHz}$, with a roll off at $24 \mathrm{~dB} /$ octave. LP was a 2-pole filter, with a $-3 \mathrm{~dB}$ point at $5 \mathrm{kHz}$, with roll off at $12 \mathrm{~dB} /$ octave. This filtering of the audio signal allowed for minimization of wheeze and snoring sounds $(200-800 \mathrm{~Hz})$ and speech $(<1 \mathrm{kHz})$. For the EMG signal, HP consisted of a 4-pole filter, with a $-3 \mathrm{~dB}$ point at $120 \mathrm{~Hz}$, with a roll off at $24 \mathrm{~dB}$ /octave. LP was similar to that of the microphone preprocessing. The signal averaging post full wave rectification had a time constant of $30 \mathrm{~ms}$.

Prior to starting recording, the cough recorder was connected to an IBM-compatible computer using an operating software (RMOS). Sampling rates of $50 \mathrm{~Hz}$ were used for the audio and EMG signals. The recording modes could be either continuous or episodic. In continuous mode, the recording can last $3-4 \mathrm{~h}$, but in episodic mode, it can record for up to $48 \mathrm{~h}$. Therefore, for $24 \mathrm{~h}$ recording, we used episodic recording triggered by a preset level of EMG activity. For each trigger, recordings of all five channels were obtained starting 2.5 $\mathrm{s}$ prior to the EMG trigger and for at least $10 \mathrm{~s}$, lasting for as long as the EMG input is at a level higher than the threshold EMG activity. If no EMG trigger occurs for $30 \mathrm{~min}$, there is an automatic recording for $10 \mathrm{~s}$.

Each channel was displayed on the screen and the audio and EMG signals were adjusted, so that distinct wave-forms following voluntary quiet and loud coughing were obtained. This ensured that the recorder was triggered by the slightest cough. All channels were then monitored in real time and we ascertained that voluntary cough signals were recorded satisfactorily prior to disconnecting the recorder from the computer. There was no difference in the recorded signals whether the subjects were in an erect or supine position.

Twenty four hours later, the recorder was reconnected to the IBM-compatible computer and the recorded data was transferred from the recorder to the hard disk. The results were then displayed on the screen and the number of coughs counted as described below. 


\section{Validation of cough events}

Differentiation of cough from other events. Subjects and patients were asked to simulate sighing, loud speech, throat-clearing and forced expiratory manoeuvres. The wave forms of these manoeuvres were displayed on the computer screen for real time monitoring. These were compared with those for voluntary coughing.

Experimental induction of cough. In 10 normal subjects, we performed cough challenges with low-chloridecontent and capsaicin solutions [18], and compared cough numbers counted by an independent observer and recorded by the portable recorder. For challenges with low-chloride content solution, subjects inhaled decreasing chloride content solution $(150,75,37.5$ and $0 \mathrm{mM}$ ) from an ultrasonic nebulizer (DeVilbiss Ultraneb 99, DeVilbiss Health Care, inc. Somerset, USA) for $1 \mathrm{~min}$, and cough counts were made during the $1 \mathrm{~min}$ and the succeeding $1 \mathrm{~min}$. For capsaicin challenge, capsaicin aerosols $(1-500 \mu \mathrm{M})$ were inhaled once in increasing twofold concentrations from a nebulizer triggered by a dosimeter for $1 \mathrm{~s}$ (Morgan "Nebucheck") Nebulizer Controller, P.K. Morgan Ltd, Kent, UK).

\section{Measurement of coughing events}

We used the audio and EMG signals as visualized on the computer screen to count coughs. Coughing events were counted either as individual events or as a cluster of single events. We defined each cluster (a "cough epoch") as a close succession of coughs recorded by each trigger of the recorder (fig 3). To analyse the diurnal variation of the coughs or cough epochs, we divided the 24 $\mathrm{h}$ into eight $3 \mathrm{~h}$ periods. Awake time was arbitrarily defined as 5 a.m. to 11 p.m. and sleep time as 11 p.m. to 5 a.m.

\section{Data analysis}

Because of the wide variation of cough numbers or epochs between the patients and their skewed distribution, data has been expressed as median cough numbers or cough epochs. Nonparametric KruskalWallis test was used to compare the relationship of cough numbers or epochs with symptom score of asthma or cough. Mann-Whitney-Wilcoxon test was used to compare the median cough numbers or epochs in the different groups. The relationship between the cough numbers or epochs and the variation in peak expiratory flow or the baseline forced expiratory volume in one

a)

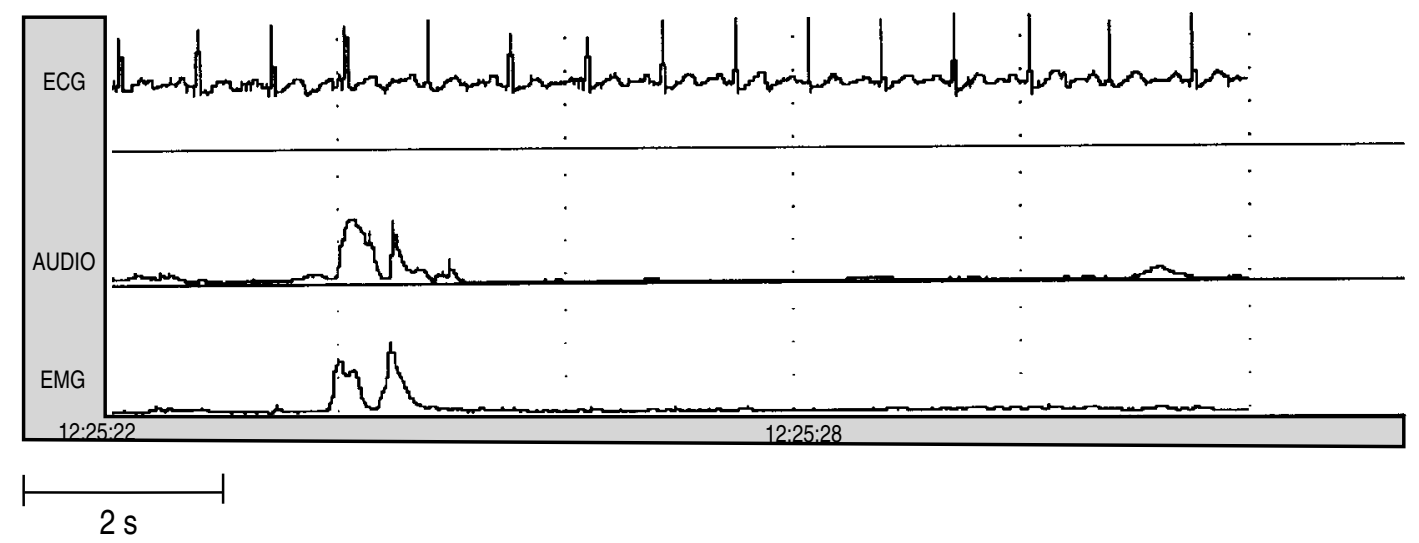

b)

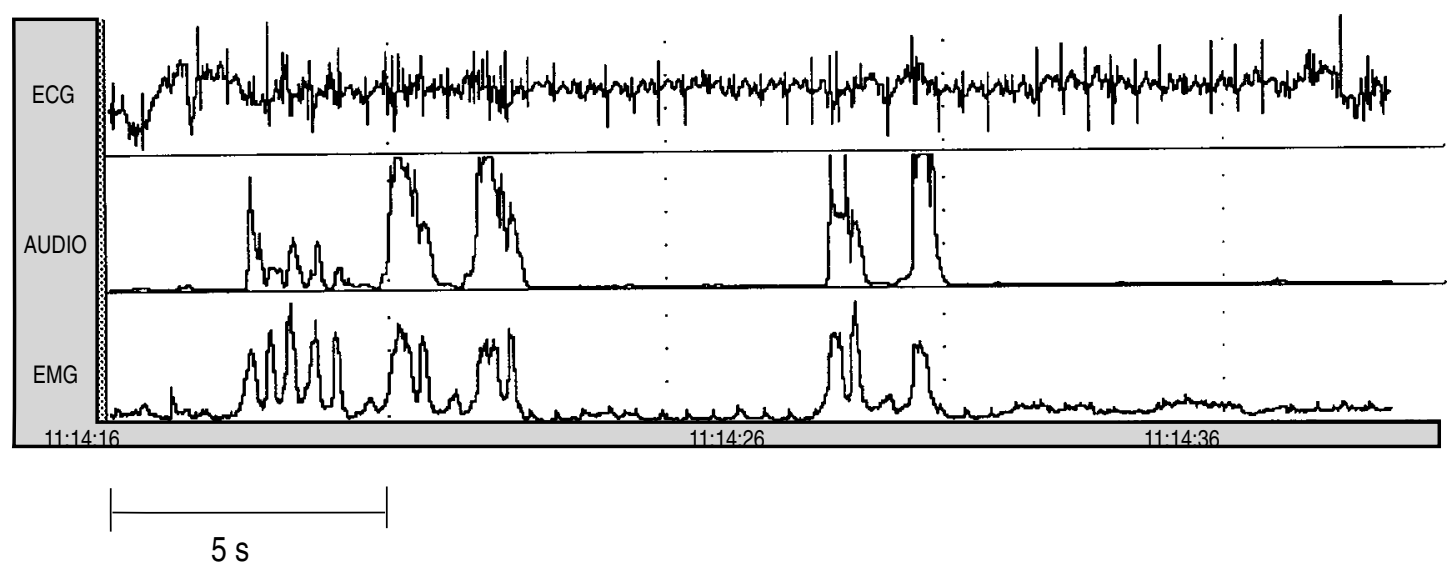

Fig. 3. - Examples of triggered recordings of spontaneous cough, lasting for $10 \mathrm{~s}$ or more. The signals recorded are (from top to bottom): electrocardiogram (ECG); audio signal (AUDIO); electromyogram (EMG); a) There are two distinct EMG peaks accompanied by simultaneous audio peaks, counted as either two separate coughs or as a single epoch, i.e. a close succession of coughs recorded on one trigger of the recorder. b) Example of one cough epoch lasting for $22 \mathrm{~s}$. The total number of individual coughs are 12 counted from the EMG signals with corresponding audio signals. 
a) Voluntary cough

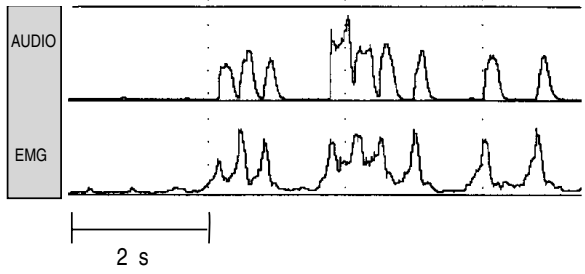

c) Laughing

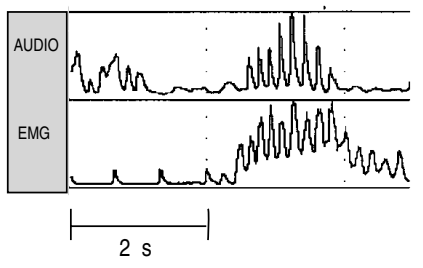

e) Throat-clearing

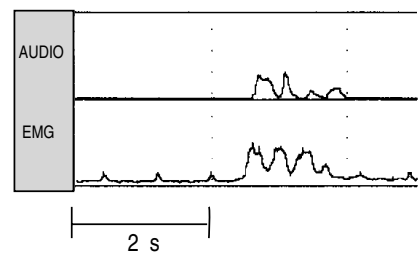

g) Peak flow monitoring

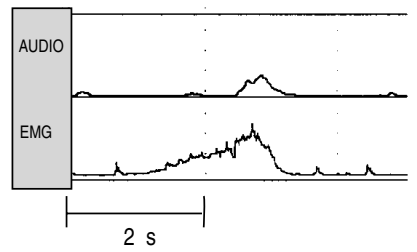

\section{b) Sneezing}

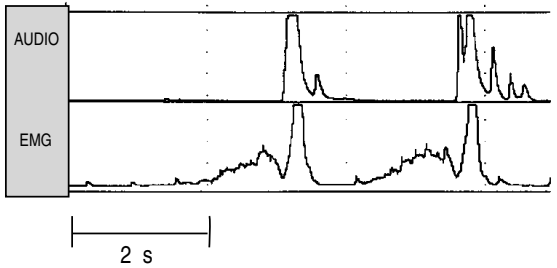

d) Speaking loudly

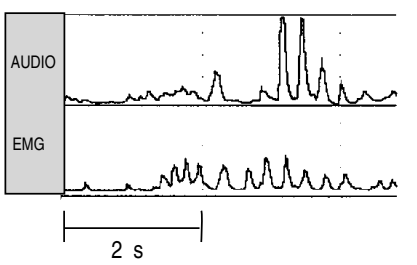

f) Using MDI inhaler

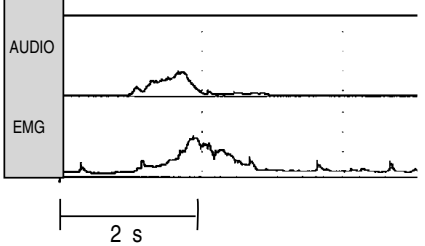

h) Forced expiratory manoeuvre

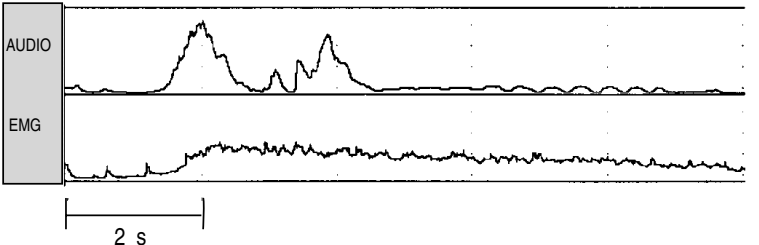

Fig. 4. - Recording of audio (AUDIO) and electromyogram (EMG) signals for various manoeuvres which could interfere with the counting of signals induced by cough. a) Voluntary cough produces distinct EMG peaks, accompanied by simultaneous audio peaks. b) Sneezing is usually accompanied by a slow rise in the EMG prior to a rapid rise in EMG and audio signal. c) Laughing induces a saw-tooth pattern in the EMG signal, without return of the EMG to baseline. d) Speaking loudly shows a dissociation between the audio and EMG signals. e) Throat-clearing produces EMG signals which are not as steep as those of cough, although it can sometimes be difficult to differentiate from signals induced by cough. Manoeuvres for: f) using a metered-dose inhaler (MDI); or g) measuring peak flow; or h) forced expiratory volume manoeuvre induce EMG and audio signals which are asynchronous and are clearly different from those of cough.

second $\left(\mathrm{FEV}_{1}\right)(\%$ predicted $)$ in asthmatic patients was determined by using Spearman rank order correlation coefficient. In order to test the inter- and intraobserver variation of cough counts, data from eight $24 \mathrm{~h}$ recordings were counted twice at different times by one observer, and once by another observer, and analysed using the method of Bland and Altman [19].

\section{Results}

\section{Patterns of audio and EMG signals}

Cough induced either voluntarily or by agents, such as low-chloride solution or capsaicin, or spontaneouslygenerated induced typical audio and EMG signals as illustrated in figure 3,4 and 5. The simultaneous rapid increase and fall both in the audio and EMG signals could be differentiated from others induced by sneezing, laughing, speaking loudly, throat-clearing, forced expiratory manoeuvre, peak flow monitoring or using a metered-dose inhaler (fig 4).

\section{Induced cough}

The patterns of audio and EMG signal induced by low-chloride content and capsaicin solutions are shown in figure 5. These are clearly different, with the former inducing a train of 2-3 coughs separated by $1.5 \mathrm{~s}$ or more, whilst the latter usually caused a burst of rapid coughs in succession. (usually 5-6 at the highest concentration). There was an excellent correlation between the total 
a)

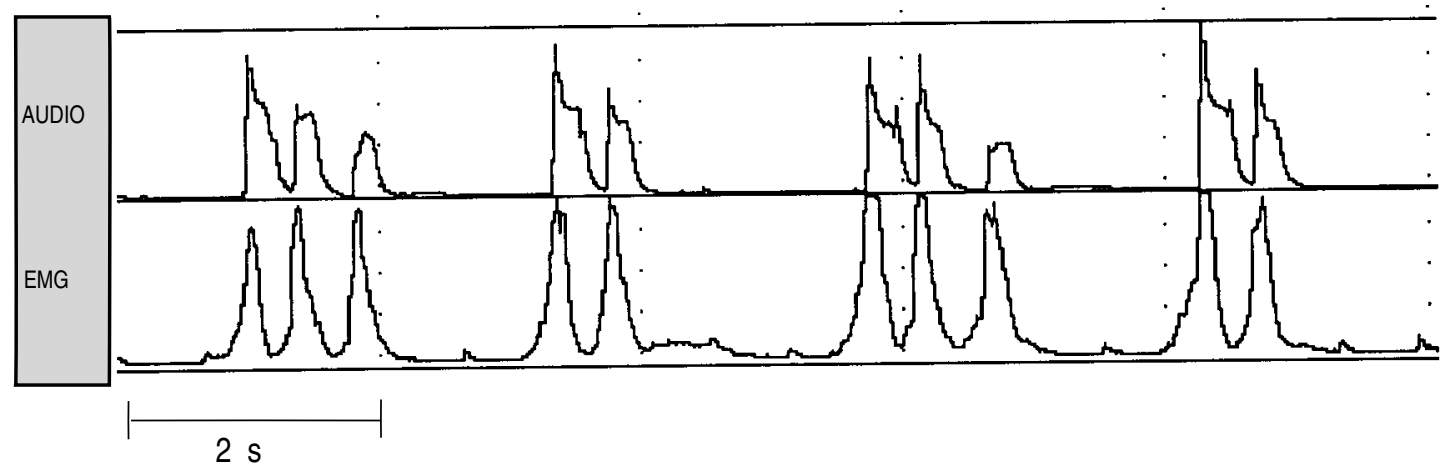

b)

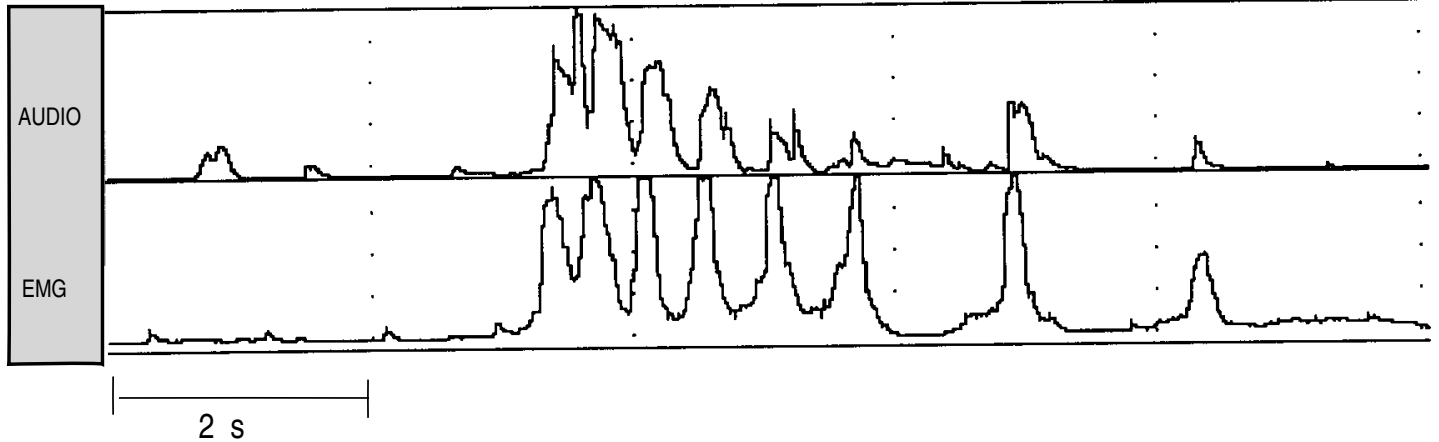

Fig. 5. - Audio (AUDIO) and electromyogram (EMG) signals obtained in a normal subject whilst coughing: a) during inhalation of lowchloride content solution; and b) following inhalation of capsaicin solution. Low-chloride content solution induced trains of 2 or 3 coughs separated by more than one second, whilst capsaicin caused a rapid train of 6 coughs followed by 2 intermittent coughs. With capsaicin, the EMG signal remains constant but the audio signal decreases with each successive cough.

coughs induced, as counted by an observer at the time of the challenge, and the coughs counted from analysis of the audio and EMG signals ( $\mathrm{r}=0.999 ; \mathrm{p}<0.005$ for lowchloride content solution challenge; and $\mathrm{r}=0.999 ; \mathrm{p}<0.005$ for capsaicin challenge).

\section{Spontaneous cough}

In the normal subjects, only occasional coughs were found (range 0-16 coughs $\cdot$ day $^{-1}$ ). In the asthmatics, the median $24 \mathrm{~h}$ cough numbers was 282 (range 45-1,577) and cough epochs 58 (range 12-263). Coughs occurred mostly in the daytime, peaking between 11 a.m. and 2 p.m. $(17 \%)$, and rarely in the night when subjects were sleeping (1.4\% between 2 a.m. and 5 a.m.) (fig. 6). There was no significant correlation between $\mathrm{FEV}_{1}(\%$ pred) and $24 \mathrm{~h}$ cough numbers. There was no significant correlation between diurnal variation of peak expiratory flow rate and $24 \mathrm{~h}$ cough numbers, and between both daytime or night-time cough numbers and daytime or night-time asthma symptom scores.

In the chronic coughers, the $24 \mathrm{~h}$ cough numbers and cough epochs were 794 (range 64-3,639) and 154 (range 21-362), respectively, which was significantly higher than that in asthmatics $(\mathrm{p}<0.05)$. The peak time of coughing was similar to that of asthmatics (19.4\% between 11 a.m. and 2 p.m.); the incidence of night-time cough was low (2.9\%, between 2 a.m. to 5 a.m.). There was a significant correlation between daytime cough numbers and daytime cough symptom scores $(\mathrm{p}<0.01)$, but not between night-time cough numbers and nighttime cough symptom scores (fig. 7).

There was a significant correlation between the total cough numbers and the cough epochs for all the $24 \mathrm{~h}$ recordings $(n=47 ; r=0.96 ; p<0.005)$. The inter- and intraobserver variation for repeat counting of coughs

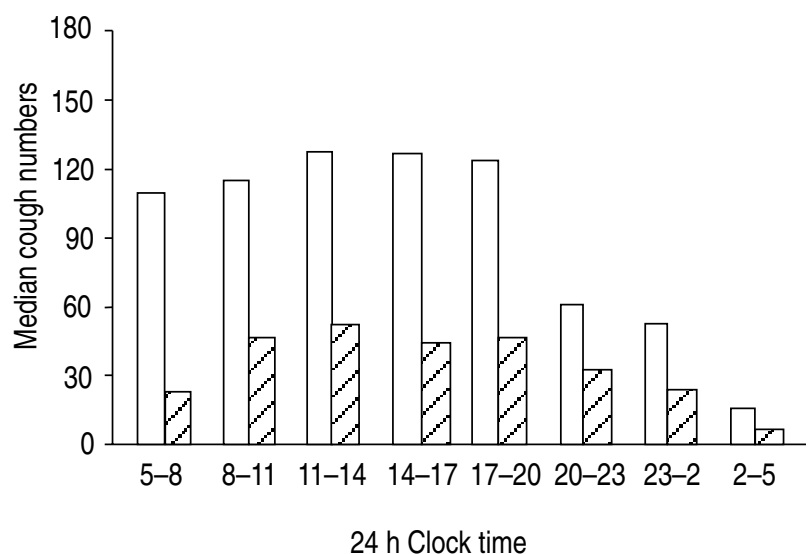

Fig. 6. - Diurnal variation of median cough numbers for chronic coughers $(\square, n=14)$ and asthmatics $(\square, n=21)$. The cough numbers recorded in 12 normal volunteers are not shown on the figure, because the median numbers were extremely low at each of these $3 \mathrm{~h}$ intervals. Chronic coughers coughed more frequently than the asthmatics at all time intervals. In both groups, there was a diurnal variation of cough frequency, with the cough numbers lower between 20.00 and $05.00 \mathrm{~h}$, the lowest between 02.00 and $05.00 \mathrm{~h}$. 

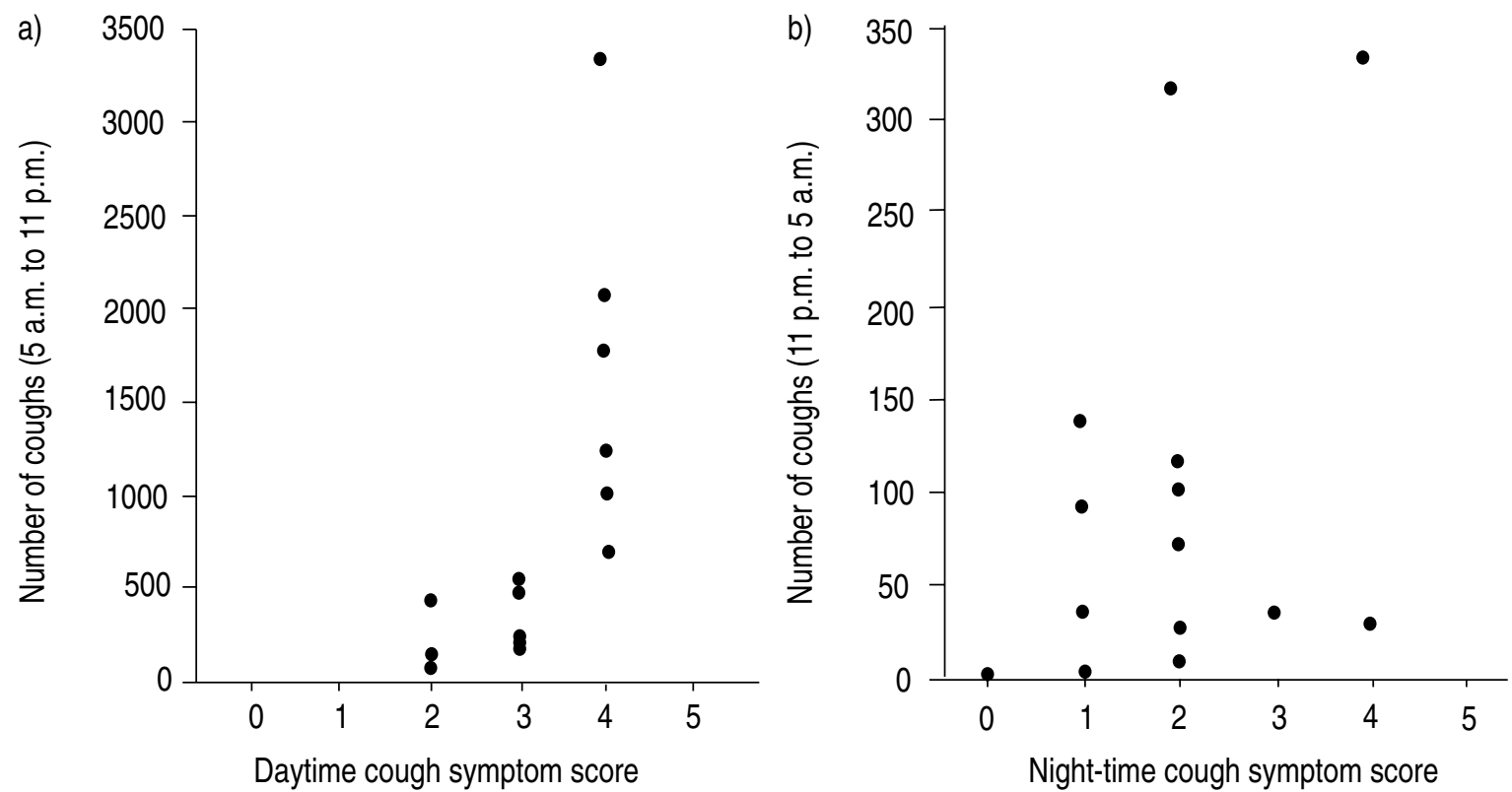

Fig. 7. - a) Relationship between daytime cough symptom score and number of coughs recorded over the awake time (5 a.m. to 11 p.m.) in chronic coughers. There is significant correlation $(\mathrm{p}<0.01)$. b) Lack of correlation between night-time cough symptom score and number of coughs recorded over the sleep time (11 p.m. to 5 a.m.) in chronic coughers.

for $24 \mathrm{~h}$ recordings containing a median number of 330 coughs (range 75-980) was within one SD of differences for seven recordings, and just outside $2 \mathrm{sD}$ 's for one.

\section{Discussion}

We describe an ambulatory system for measuring the frequency of coughs over a $24 \mathrm{~h}$ cycle. In addition to the use of a sensitive microphone to register sounds, we also used surface electrodes to pick up EMG activity of the respiratory muscles, including that of the diaphragm. The EMG signal was used to trigger the system to record, thus excluding registration of much extraneous noise. Using the sound and EMG signals, we could differentiate the patterns induced by a cough from those caused by other noises. The major advantages of our recording system include portability, which interferes to a minimum with the subject's mobility, and a relatively rapid and dependable counting of the cough frequency during the $24 \mathrm{~h}$ cycle. Although microphones connected to a tape-recorder have been used in the past to record cough frequency [15, 16], counting of the cough numbers could only be performed in real time. In our recording system, the coughing events can be rapidly scanned and counts of individual coughs be made. Because the number of coughs were closely correlated to the number of cough "epoch", i.e. a close succession of coughs recorded by each trigger of the recorder, it would be quicker to make a count of the cough epochs by enumerating the number of triggers induced by coughs.

The cough profile from the sound and EMG signals could be differentiated from other profiles. The simultaneous rapid upstroke and downstroke of the two signals are typical for cough, as illustrated during voluntary cough or during cough induced by tussive agents, such as lowchloride content and capsaicin solutions (fig. 5). It was not difficult to distinguish the typical cough signals from the extraneous ones, such as talking loudly, laughing, performing peak flow manoeuvres, using a metered-dose inhaler and sneezing. The cough signals are also distinct from snoring and wheezing. The sensitivity of the trigger for recording was set for each subject and was the minimum threshold trigger for the EMG recording. Because EMG signals were used to trigger the recorder, this produced less extraneous signals to be recorded compared to previous recorder systems triggered by sound $[15,16]$. The magnitude of the signals was not affected whilst in the prone position, and does not explain the lower frequency of coughs whilst lying supine in bed. Finally, both the intraobserver and interobserver variabilities for measuring the number of coughs were low and acceptable. A software to count the coughs is currently under development.

We found in our sample of chronic coughers a significantly higher number of coughs and cough epochs throughout the $24 \mathrm{~h}$ cycle when compared to the asthmatics $(\mathrm{p}<0.05)$. However, there was a large overlap in the numbers of cough in the two groups, and the range of cough counts was wide, representing a $40-60$ fold difference between the lowest and the highest cough numbers recorded in the two groups. This illustrates the very wide range of spectrum of the degree of cough as a symptom from patient to patient, and also from disease to disease [20].

Of great interest is the marked diurnal variation in the cough frequency in both groups of coughers, with the lowest number of coughs during the 2-5 a.m. period, when only $2.2 \%$ of the total number of coughs was observed. For both groups, the cough frequency stayed at a fairly constant level between 5 a.m. and 8 p.m. after which it gradually fell to its lowest during the 2-5 a.m. period. Part of the diurnal variation may be related to sleep itself, because POwER et al. [21] demonstrated that spontaneous cough is suppressed during sleep as determined by ECG 
in patients with chronic bronchitis. A similar diurnal variation in cough count in young adults during natural colds has been described using a nonambulatory recording system [22]. This diurnal variation of cough frequency, particularly in asthmatics, may appear surprising as nocturnal coughing is regarded a classical feature of asthma [1,2]. However, our patients were in a relatively stable clinical state and not with an impending exacerbation of asthma, and were on maintenance anti-inflammatory therapy, usually inhaled corticosteroids. In two asthmatic patients with impending exacerbation, we have found that cough persisted throughout the $24 \mathrm{~h}$ of recording with no diurnal variation, and disappeared following treatment of the exacerbation with corticosteroid therapy.

Although the development of nocturnal coughing may be a feature of impending worsening of asthma, we found no significant relationship between cough frequency and diurnal variation in peak expiratory flow rates used as a measure of the severity of asthma in our study. In addition, there was no relationship between the patient's perception of his asthma and cough, and, also, no relationship between the number of coughs and asthma symptom score. Although this relationship needs to be examined in patients with a wider spectrum of severity of asthma, our data suggest that the number of coughs is independent of the degree of underlying airways obstruction. Other investigators have reported that detailed analysis of the sound spectra of the cough sounds from asthmatic patients may differ from those recorded from nonasthmatic patients [23, 24]. However, this may only be useful in diagnosis rather than in determining the severity of asthma. We have also found that some normal subjects experienced a small number of coughs mainly during the daytime hours (not more than 16 coughs in all). This may represent cough as a defensive mechanism.

In the chronic coughers, there was a good correlation between the cough numbers during the day and the patient's scoring of cough severity, indicating that these patients had a better perception of their cough than the patients with stable asthma. However, appreciation of the cough severity at night was poor in both the chronic coughers and the asthmatics.

We describe a reliable method for obtaining cough counts over a $24 \mathrm{~h}$ cycle in fully ambulatory patients. One of its strengths is that it provides an objective and accurate means of assessing the effect of potential antitussive agents in patients with various pulmonary conditions characterized predominantly by cough, and in whom suppression of cough is important.

\section{References}

1. Carrao WM, Braman SS, Irwin RS. Chronic cough as the sole presenting manifestation of bronchial asthma. N Engl J Med 1979; 300: 633-637.

2. McFadden ER. Exertion dyspnoea and cough as preludes to acute attacks of bronchial asthma. N Engl J Med 1975; 292: 555-559.

3. Irwin RS, Curley FJ, French CL. Chronic cough: the spectrum and frequency of causes, key components of the diagnostic evaluation, and outcome of specific therapy. Am Rev Respir Dis 1990; 141: 640-647.
4. Cass LJ, Frederik WS. Evaluation of a new antitussive agent. $N$ Engl J Med 1953; 249: 132-136.

5. Woolf CR, Rosenberg A. The cough suppressant effect of heroin and codeine: a controlled clinical study. Can Med Assoc J 1962; 87: 810-814.

6. Bickerman HA, Barach AL. The experimental production of cough in human subjects induced by citric acid aerosols. Preliminary studies on the evaluation of antitussive agents. Am J Med Sci 1954; 228: 156-163.

7. Archibald DW, Slipp LB, Shane SJ. Short communication. The evaluation of a cough suppressant: an exercise in clinical pharmacology. Can Med Assoc J 1959; 80: 734-746.

8. Morris DJ, Shane SJ. Human bioassay of a new antitussive agent. Can Med Assoc J 1960; 83: 1093-1095.

9. Prime FJ. The assessment of antitussive drugs in man. Br Med J 1961; 1: 1149-1151.

10. Calesnik B, Christensen JA, Munch JC. Antitussive action of L-propoxyphene in citric acid-induced cough response. Am J Med Sci 1961; 242: 560-564.

11. Chernish SM, Lewis G, Kraft B, Howe J. Clinical evaluation of a new antitussive preparation. Ann Allergy 1963; 21: 677-682.

12. Cass LJ, Frederik WS, Andosca JB. Quantitative comparison of dextromethorphan hydrobromide and codeine. Am J Med Sci 1954; 227: 291-296.

13. Konar NR, Dasgupta S. A chemical method for exciting cough reflex in human beings and its use in assessing the effectiveness of cough sedatives. J Indian Med Assoc 1959; 32: 189-193.

14. Gravenstein JS, Devloo RA, Beecher HK. Effect of antitussive agents on experimental and pathological cough in man. J Appl Physiol 1954; 7: 119-139.

15. Woolf CR, Rosenberg CR. Objective assessment of cough suppressants under clinical conditions using a tape recorder system. Thorax 1964; 129: 125-130.

16. Sevelius H, Colmore JP. Objective assessment of antitussive agents in patients with chronic cough. J New Drugs 1966; 6: 216-223.

17. Salmi T, Sovijarvi ARA, Brander P, Piirila P. Longterm recording and automatic analysis of cough using filtered acoustic signals and movements on static charge sensitive bed. Chest 1988; 94: 970-975.

18. Vantresca P, Nichol GM, Barnes PJ, Chung KF. Inhaled furosemide inhibits cough induced by lowchloride content solutions and not by capsaicin. Am Rev Respir Dis 1990; 142: 143-146.

19. Bland JM, Altman DG. Statistical methods for assessing agreement between two methods of clinical measurement. Lancet 1986; i: 307-310.

20. Loudon RG, Brown LC. Cough frequency in patients with respiratory disease. Am Rev Respir Dis 1967; 98: 1137-1143.

21. Power JT, Stewart IC, Connaughton JJ, Brash HM, Shapiro CM. Nocturnal cough in patients with chronic bronchitis and emphysema. Am Rev Respir Dis 1984; 130: 999-1001.

22. Kuhn JJ, Hendley JO, Adams KF, Clark JW, Gwaltney Jr JM. Antitussive effect of guaifenesin in young adults with natural colds: objective and subjective assessment. Chest 1982; 82: 713-718.

23. Thorpe CW. Towards a quantitative description of asthmatic cough sounds. Eur Respir J 1991; 5: 685692.

24. Piirila P. Sovijarvi AR. Differences in acoustic and dynamic characteristics of spontaneous cough in pulmonary diseases. Chest 1989, 96: 46-53. 